\title{
GÊNEROS DO DISCURSO E APROPRIAÇÃO DE SABERES: (RE)CONHECER AS PRÁTICAS LINGUAGEIRAS EM SALA DE AULA*
}

Maria de Lourdes Meirelles Matencio**

\begin{abstract}
Resumo: Toda atividade social pressupõe a realização de ações de linguagem. Parece ser essencial, por essa razão, que as aulas de língua materna centrem-se, nos diferentes níveis de ensino, nas dinâmicas sociais de interação como formas de desencadear os processos de aprendizagem visados. À luz desse ponto de vista, este texto discute a relevância de se trabalhar com os gêneros do discurso - concebidos como gêneros de atividades interacionais -, a fim de garantir a construção de saberes essenciais para a atuação do sujeito nas diversas práticas de linguagem com as quais vier a se deparar.
\end{abstract}

Palavras-chave: gênero do discurso; letramento; prática de linguagem; atividade.

L'intelligence individuelle n'est qu'un moment, qu'une expression d'un processus plus complexe, de nature sociale.

(DOISE; MUGNY)

\footnotetext{
* A discussão aqui apresentada é resultado de investigações que tenho desenvolvido no âmbito do grupo que coordeno na PUC Minas, Leitura, produção de textos e construção de conbecimentos (LePTeCCo), do grupo Letramento do professor (coordenado pela professora doutora Ângela Kleiman, com sede no IEL/UNICAMP) e do convênio CAPES/COFECUB (sob coordenação do professor doutor Manoel Luiz Gonçalves Corrêa, da FFCHL/USP). A realização deste trabalho também não teria sido possível sem o financiamento de diversas agências e instâncias de fomento (CNPq, CAPES, COFECUB, FAPEMIG, FAPESP, FIP/PUC Minas).

* Professora da PUC Minas. Doutora em Lingüística Aplicada. E-mail: <maria.matencio@pq.cnpq.br>.
} 


\section{DISCURSOS SOBRE A CIÊNCIA, DISCURSOS DA CIÊNCIA}

$\mathrm{O}$ interesse crescente nas redes de atividades que configuram as aulas de língua materna tem promovido o desenvolvimento de um conjunto de trabalhos que em muito iluminam a relação entre concepções e abordagens de ensino, bem como entre práticas em sala de aula e processos de aprendizagem (cf. BRONCKART, 2006; CELANI, 1992; KLEIMAN, 1992; MACHADO, 2004; MATENCIO, 2001) ${ }^{1}$.

Mas se a consolidação desse viés investigativo e analítico foi importante para muitos dos deslocamentos ocorridos nas práticas de formação de professores, seus efeitos na Educação Básica têm sido fruto de maior polêmica (KLEIMAN, 2001; KLEIMAN; MATENCIO, $2005)^{2}$. Certamente, isso não ocorre por razões especificamente acadêmico-científicas.

Assim como os avanços nas tecnologias da informação promoveram, nos últimos trinta anos, a emergência de novos gêneros e atividades de interação ${ }^{3}$, essas tecnologias revolucionaram a produção, circulação e recepção de textos, levando ao aparecimento de múltiplas e

${ }^{1}$ Uma ilustração do impacto desses estudos pode ser verificada, inclusive, em outros campos de formação de professores (cf., por exemplo, MORTIMER; SMOLKA, 2001).

2 É, sem dúvida, necessário e relevante considerarmos as diversas tentativas que, no âmbito das políticas públicas de educação, voltaram-se à difusão de propostas de mudanças nas práticas de formação e atuação dos professores. Dentre tais tentativas encontram-se, por exemplo, a elaboração e regulamentação das Diretrizes Curriculares para a Formação de Professores da Educação Básica e das Diretrizes dos Cursos de Letras, que buscaram alterar não apenas os eixos das matrizes curriculares como também os espaços e tempos dedicados às práticas (investigativas, de estágio, culturais); a elaboração e reelaboração dos Parâmetros Curriculares Nacionais dos Ensinos Fundamental e Médio (consecutivamente, PCN e PCNEM), que procuraram atribuir ênfase mais consistente ao trabalho com as práticas de linguagem; ou a implantação do Plano Nacional do Livro Didático (PNLD), que tem buscado articular o material didático disponível ao professor às propostas de parametrização do ensino. Mas não podemos, tampouco, negar as inúmeras polêmicas que têm suscitado essas políticas públicas, seja pelo modo como vêm sendo conduzidas, seja no que se refere às lacunas que apresentam ou ao baixo impacto promovido.

3 Considerando-se que o processo de desenvolvimento da linguagem dá-se nas práticas de socialização do sujeito e, ainda, que os gêneros do discurso emergem em tais práticas, então se pode concluir que os sujeitos constroem "modelos" de ação de linguagem - saberes sobre as formas de dizer, fazer, compreender e produzir sentidos -, nas atividades interacionais em que se encontram engajados; daí minha opção por conceber os gêneros do discurso como gêneros de atividades interacionais (cf. MATENCIO, 2003, 2005, 2006a, 2006b, para uma discussão mais detalhada dessas questões).

MATENCIO - Gêneros do discurso e apropriação de saberes... 
diferentes demandas sociais de formação na Educação Básica ${ }^{4}$. Essas mudanças são freqüentemente tematizadas quando se divulgam os resultados insatisfatórios obtidos pelos alunos nos diversos sistemas de avaliação ou quando se apresentam os dados relativos às dificuldades que enfrentam ao ingressarem no mercado de trabalho ou na universidade. Os debates em torno da questão parecem indicar a existência de um pretenso consenso social em relação ao perfil do cidadão que a escola precisaria formar. A midiatização do aparente fracasso das práticas escolares de ensino de línguas e das políticas públicas para a educação tem, de fato, difundido, em diferentes instâncias sociais, a idéia de que o aluno deveria desenvolver determinadas habilidades de leitura e escrita bem como as competências que lhe são subjacentes.

Mas, quando se trata de demarcar os possíveis percursos que criariam condições para o desenvolvimento de habilidades e competências, há muito dissenso. Além disso, na arena em que ocorrem as disputas, também largamente midiatizadas, sobressaem os discursos simplificadores dos processos de ensino/aprendizagem. Contradizem-se, cotidianamente, e com enorme tranqüilidade, os resultados de trabalhos de cunho acadêmico-científico que assinalam tanto a ineficiência de práticas centradas nas tradicionais gramáticas pedagógicas quanto a limitação de se tentar impor às escolas de "um país com dimensões continentais" um programa curricular único. Não é raro, assim, que se faça referência ao que seria a "posição" equivocada de "alguns poucos lingüistas e educadores", quando repudiam o ensino de línguas centrado no código, ou que se considere mera bravata a defesa de aulas que elejam objetos de ensino produzidos na interface entre as forma e os sentidos, entre o texto e o contexto.

Os conflitos entre saberes científicos e as representações predominantes nos discursos sociais parecem-me vinculados à idealização - infelizmente, muitas vezes promovida pelos próprios pesquisadores - do impacto social possível da produção acadêmicocientífica. Isso ocorre em função de se desconsiderar o peso

\footnotetext{
${ }^{4}$ Tais mudanças, por sua vez, trouxeram a público as relações complexas entre os problemas sociais e as dificuldades estruturais com as quais a escola lida desde a chamada democratização da educação dos anos 1970, a qual representou, como se sabe, uma tentativa malograda de "universalização da escola" com a mera abertura de vagas na rede pública, como um conjunto de produções acadêmico-científicas vinha assinalando há bastante tempo em nossa área.
} 
determinante das contingências a esse conhecimento, isto é, das representações arcaicas com as quais ele se defronta, das condições sócio-históricas e estruturais em que ele emerge e se realiza, das limitações decorrentes do estágio em que se encontram paradigmas a ele relacionados e, por fim, das redes de atividades com as quais, direta ou indiretamente, ele se relaciona ${ }^{5}$.

Nesse contexto, qualquer agenda que nos disponhamos a estabelecer para a área deveria considerar como relevante a discussão dos possíveis (e prováveis) efeitos dos saberes produzidos no campo dos estudos da linguagem - e por que não dizer nas Ciências Humanas? para as transformações sociais (BRONCKART, 2008; RAJAGOPALAN, 2003).

Em outros termos, parece-me hora de recolocarmos em pauta discussões sobre projetos de difusão social dos saberes produzidos no domínio $^{6}$, que salientem a natureza política de nossa atuação e a necessidade de que ela provoque, em curto prazo, impactos sociais efetivos e amplos. Se esse tipo de afirmação não pretende negar que o discurso - aquilo pelo que se luta! (como nos lembra Foucault) ${ }^{7}-$, de fato, constrói o real, em meio à diferença e à divergência, à ambigüidade e à polissemia, não ignora também que, ainda assim, o real insiste sempre em emergir, e sempre nas brechas do discurso que, dialeticamente, pretende domá-lo; daí podermos acreditar no saber fazer das práticas científicas!

Procurando adotar essa linha de raciocínio, tenho defendido, em publicações e em diferentes fóruns nos quais atuo, aquelas que seriam, a meu ver, as tarefas dos estudos da linguagem. Dentre elas, procuro ressaltar a importância que têm, e os avanços que nos proporcionaram,

\footnotetext{
${ }^{5}$ Para se ter uma idéia, já em 1946, Bloomfield, em obra retomada por Chiss e Puech (1999), ao refletir sobre o impacto internacional da Lingǘstica, ressalta a distância entre o campo dos estudos lingüísticos e as práticas escolares.

${ }^{6}$ Nesse sentido, o desenvolvimento de pesquisas-ação ou de intervenção, as quais foram, muitas vezes, duramente criticadas - até porque, dadas as políticas públicas de formação em nível de pósgraduação, não há condições de serem desenvolvidas em pesquisas de mestrado -, deveria ser mais detalhadamente considerado, seja no âmbito dos trabalhos de doutorado, seja no seio de grupos de pesquisa. Afinal, trata-se de procedimento acadêmico-científico salutar, uma vez que propõe um fazer com os sujeitos, e não apenas um falar sobre os sujeitos ou um falar para os sujeitos.

7 Refiro-me, particularmente, à reflexão empreendida pelo autor no livro $\mathbf{A}$ ordem do discurso (Loyola, 1998).
}

MATENCIO - Gêneros do discurso e apropriação de saberes... 
as pesquisas acerca: (a) do processo de aquisição e de desenvolvimento da língua(gem); (b) do funcionamento da língua(gem) nos textos e nos discursos; e (c) das práticas de ensino e de aprendizagem da língua(gem) (MATENCIO, 2006b).

Tenho procurado, também, salientar que priorizar essas questões na agenda dos estudos da linguagem, em programas de pesquisa, ensino e ação social, não representa, como uma leitura rápida poderia levar a se concluir, uma tentativa de apagar conflitos e divergências internos ao campo. Não se trata, tampouco, de ignorar a relevância das chamadas pesquisas de base, que proponham a investigação de aspectos direta ou exclusivamente vinculados ao sistema lingǘstico.

Trata-se, ao contrário, de acentuar a importância de uma visão integrada dos "fatos" linguageiros, que só pode ser alcançada quando se tem clareza de que os objetos que se podem construir no campo dos estudos da linguagem vão muito além dos fenômenos relativos ao funcionamento da língua. Trata-se, portanto, de assumir que elucidar os "fatos" lingüísticos - por sua identificação, classificação e/ou descrição é tarefa que cria condições para a realização de investigações em que os fatos linguageiros sejam tomados tais como são empiricamente apreendidos pelos sujeitos, sejam eles experts ou não.

Afinal, uma análise integrada de recursos linguageiros permite, em princípio: (a) a identificação e classificação de determinadas regularidades no funcionamento da língua nos textos e destes nas práticas discursivas; (b) a identificação da relevância e a descrição de aspectos propriamente lingüísticos - fonológicos, morfológicos, sintáticos, semânticos - nos (con)textos em foco; (c) o recurso a abordagens metodológicas - relativas à elaboração de instrumentos, geração e coleta de registros, organização de dados ou sistematização de categorias de análise - que possibilitam um olhar o suficientemente abrangente para se compreender, descrever e explicar o quê, como e por quê os sujeitos fazem o que fazem quando usam a linguagem. Ou seja, uma análise dessa natureza procura identificar tanto o que é efeito do sistema lingüístico no funcionamento dos discursos quanto o que é efeito das práticas discursivas na estabilidade e transformação do sistema 
lingüístico, incorporando na descrição, quando é o caso, o recurso a outros sistemas simbólicos ${ }^{8}$.

Uma perspectiva como a proposta busca, pois, integrar o estudo da língua ao estudo dos textos e dos discursos, assim como a análise de diferentes sistemas e subsistemas semióticos pelos quais ganham materialidade as ações de linguagem do sujeito. Por isso mesmo, permite que se abordem, sem rupturas, as relações entre o social e o individual, entre práticas coletivas e cognição humana, contemplando a centralidade da linguagem nos processos subjetivos e sociais.

\section{REPRESENTAÇÕES: DOS MOVIMENTOS INTERACIO- NAIS À APRENDIZAGEM}

Feitas essas reflexões iniciais, passemos a discutir por que razões essa linha de raciocínio nos conduz a atribuir função central ao estudo dos gêneros do discurso nos processos de ensino/aprendizagem, como forma de inserção dos sujeitos nas práticas sociais.

Ora, como previamente assinalado, a linguagem é condição para a existência do humano e da História, ou seja, do sujeito, do tempo e do espaço, como fenômenos que estruturam e sustentam as redes conceituais com as quais o real - tomado em sua realidade possível - é percebido em elementos discretos. Os sistemas semióticos mediante os quais a capacidade de linguagem funciona são, em outros termos, condição para a construção de artefatos simbólicos: "instrumentos" aos quais os sujeitos recorrem para realizar suas ações em atividades coletivas e para construir representações mentais da realidade, as quais lhes permitem interagir; tais instrumentos são, por isso mesmo, sociocognitivos (cf. VYGOTSKY, 1989, 1991).

\footnotetext{
${ }^{8}$ Esse é o caso, por exemplo, das ações que temos desenvolvido no grupo de pesquisa Leitura, produção de textos e construção de conhecimentos - LePTeCCo, da PUC Minas -, em que o estudo da linguagem e do funcionamento dos textos e dos discursos serve tanto para que se ilustrem fenômenos linguageiros que merecem ser estudados pelos profissionais em formação quanto para que se busquem alternativas viáveis de formação de professores e para realimentar as discussões mais especificamente teóricas de outras linhas de pesquisa.
}

MATENCIO - Gêneros do discurso e apropriação de saberes... 
Parece-me pouco, entretanto, limitarmo-nos a dizer que uma representação mental (ou individual) vincula-se a uma representação social (ou "coletiva"), o que permitiria o compartilhamento de informações entre os sujeitos. Afinal, se não há imanência do sentido nos suportes ou artefatos materiais dos quais se constituem os sistemas semióticos é justamente porque eles são interpretados como artefatos simbólicos e, portanto, como efeito de ações individuais cuja significação se estabelece no seio de coletividades. Nesse sentido, pois, a imbricação entre representação mental e social é resultado de o "artefato simbólico" como instrumento que é -, a um só tempo, representar, apresentar e materializar a realidade para os sujeitos; daí se poder dizer que sua estabilidade é resultado de sua existência ao mesmo tempo individual e social.

Uma noção que parece essencial para compreender esse raciocínio é a de aparelho psíquico de produção de linguagem (SCHNEUWLY, 1988), porque apresenta condições de elucidar tanto como se organizariam globalmente as operações mentais que sustentam as ações de linguagem do sujeito quanto a direção em que se concretizaria o desenvolvimento de suas capacidades de linguagem (BRONCKART, 2008).

Mesmo que nem sempre se faça referência a essa noção, ela é, sem dúvida, um postulado de base para pesquisadores que aderem à abordagem defendida pelo grupo de Genebra (BRONCKART, 1999; SCHNEUWLY, 1988) e crucial para a consolidação teórica, metodológica e analítica dessa perspectiva. Isso se justifica porque a noção de aparelho psíquico de producão de linguagem sustenta princípio central dos trabalhos desenvolvidos desse ponto de vista, a saber, o de que as bases do desenvolvimento do sujeito vinculam-se, sim, a uma dimensão especificamente biológica, mas implicam, além de processos intrasubjetivos, processos intersubjetivos, nos quais se dão a construção de "artefatos simbólicos", materialidades semióticas relativamente estáveis e convencionais.

Dessa perspectiva, como a adotada neste trabalho, o sujeito realiza ações de linguagem - concebidas como as ações significantes flagradas em sua dimensão individual (LEONTIÉV, 1978; BRONCKART, 2005, 2006, 2008) - em atividades de interação social - situações em que suas ações realizam-se no contexto de uma coletividade (LEONTIÉV, 1978). É nesses espaços de troca que o sujeito constrói, elabora e/ou reelabora 
padrões interacionais, isto é, saberes sobre como agir nos contextos sociais. Portanto, é nas interações sociais de que participam que os sujeitos, fundamentados em sua prévia experiência cultural e intercultural, selecionam determinadas formas de conceber e de se referir aos objetos, o que os leva a determinadas ações significantes no processo de negociação de sentidos. Dito ainda de outro modo, é justamente nas interações sociais que o sujeito, em razão da interlocução que aí estabelece, se depara com a tarefa de textualizar de uma certa maneira para se fazer compreendido. A realização de suas ações de linguagem envolve tanto a seleção de itens lexicais, que se relacionam a campos conceituais construídos em sua experiência com as diferentes formas de manifestação da linguagem, quanto a textualização, que implica, por sua vez, a negociação de sentidos, in presentia ou in absentia.

Como decorrência desse raciocínio, pode-se concluir que a ação de linguagem: (a) ganha materialidade por meio de recursos linguageiros; (b) envolve operações de textualização; (c) pressupõe o compartilhamento de saberes; (d) é essencialmente classificatória; (e) implica a construção de representações mentais; (f) relaciona diferentes campos conceituais.

\section{O PAPEL DOS GÊNEROS DO DISCURSO NO DESENVOLVIMENTO HUMANO}

Como salientam alguns autores (CORDIER, 1994), no processo de desenvolvimento do sujeito, a formação de um conceito tem, como ponto de partida, um significado-nuclear vinculado a um referente conceitual $^{9}$. É em sua experiência cotidiana que o próprio sujeito, processualmente, atribui características funcionais ao referente, além de estabelecer relações entre o referente, as ações em que ele aparece e as pessoas que as realizam/localizam.

\footnotetext{
9 Os termos efetivamente utilizados pelo autor são "significado-nodal" e "objeto". Dada a especificidade deste trabalho, a opção foi substituir esses termos, respectivamente, por "significado-nuclear" e "referente", este último compreendido como um objeto-de-discurso, nos termos de Koch (2002) e Mondada e Dubois (2003).
}

MATENCIO - Gêneros do discurso e apropriação de saberes... 
O processo de formação de um conceito envolveria, portanto, a síntese de relações variadas entre o significado-nuclear do referente conceitual e os de outros referentes passíveis de identificação com base nesse mesmo nódulo funcional. Paralelamente, um conjunto de traços remetendo a propriedades do referente seria abstraído e acrescentado ao nódulo. Esse processo de elaboração conceitual se daria, inicialmente, por meio da apreensão global do referente, desenvolvendo-se, posteriormente, no sentido da elaboração de representações mentais através de operações analíticas.

Cordier (1994) assinala, ainda, a essencialidade das categorias semânticas relativas a objetos, estados, eventos, ações e relações causais, temporais, topológicas, etc. - para a organização das representações de um sujeito ${ }^{10}$.

O script - ou uma seqüência de ações estereotipadas - parece ser, segundo esse ponto de vista, um esquema cognitivo elementar no processo de desenvolvimento do sujeito, essencial no acionamento e transformação de diferentes esquemas de ação - ou seja, são esquemas relativos a como agir e regular suas condutas (BRONCKART, 2005; HOUDÉ, 2008). O script parece ser, portanto, um esquema cognitivo crucial na atividade de textualização, a qual envolve, como já salientei em outras ocasiões (MATENCIO, 2003, 2005, 2006a): (a) o planejamento de ações orientadas para um fim e sua execução em material linguageiro; (b) a ativação de determinados esquemas de ação estáveis na memória; e (c) o acionamento de certos conhecimentos lingüísticos, textuais, discursivos, referenciais.

Não se pode, complementarmente, ignorar que produzir ou compreender um texto é elaborar uma representação mental, em que há integração entre um esquema textual e um esquema de situação, num modelo circunstanciado e integrativo de diferentes saberes, em que a

\footnotetext{
${ }^{10}$ Para o autor: (a) as representações de um estado dizem respeito a situações em que um mesmo objeto pode assumir, sucessivamente, diferentes valores em relação a um certo atributo; (b) as representações de um evento referem-se a mudanças reconhecidas com base no sistema perceptivo; e (c) as representações de ações remetem a mudanças ocasionadas por um agente seja motivando-as, seja impedindo-as -, o que significa dizer que as representações de ações implicariam a representação de um evento, da própria ação e da intenção que lhes é subjacente, assim como das condições em que elas ocorrem, das relações de causalidade entre intenção e realização e entre realização e resultado.
} 
informação perceptiva coordena-se com a que se tem estocada de forma estável na memória.

Para ilustrar esse raciocínio, basta que se considere a necessidade de o sujeito lidar - seja na leitura, na escrita ou na análise de textos com diferentes scripts, ora acionando representações de relações entre parte/todo, ora evocando representações de relações temporais ou causais, ora lidando com representações de informações vinculadas a ações e eventos que lhe são familiares. As operações que subjazem à ativação desses modelos mentais são aquelas que levarão o sujeito a fazer inferências - acerca do que é dito, do modo de dizer, da situação em que se diz -, guiando-o em suas ações, de forma a reiterar ou promover novos significados, consolidar ou desenvolver esquema(s) de ação e os conhecimentos a eles vinculados.

Ora, o gênero é um instrumento semiótico que representa, como nos lembra Schneuwly (2004) numa retomada atenta da proposta bakhtiniana (2000 [1979]): "uma configuração estabilizada de vários subsistemas semióticos". Ele nada mais é do que a representação sociocognitiva pela qual se atribuem significados a objetos, estados, eventos, ações e relações; é a representação pela qual, portanto, constroem-se e transformam-se, do ponto de vista filogenético e ontogenético, representações estáveis - mentais e sociais - dos sujeitos em interação (seus papéis sociais, seu status, suas posições, etc.) e do mundo (das materialidades que o constituem, das práticas que configuram as redes interacionais, das ideologias que as orientam, etc.).

Desse ponto de vista, um trabalho com dinâmicas interacionais nas quais os gêneros do discurso emergem e funcionam permitiria, por princípio, a ativação, pelos sujeitos, de esquemas de ação que favoreceriam o acionamento e a articulação de determinadas operações e representações mentais que, por sua vez, levariam o aprendiz a realizar ações - cognitivas e metacognitivas - sobre e com as suas próprias ações e as dos outros. Desse modo, o funcionamento dos gêneros nas práticas educacionais é ocasião para que se favoreça a aprendizagem, na medida em que esse procedimento possibilita que se convoquem modelos lingüísticos, textuais, contextuais, discursivos, referenciais - a partir dos quais o sujeito pode sustentar a planificação da produção ou da leitura do texto. 


\section{CONSCIENTIZAR-SE DA SOCIALIZAÇÃO: GÊNEROS E DESENVOLVIMENTO DO SUJEITO}

Seja para delimitar a noção de representação, seja para assumi-la como categoria central na orientação de nossas escolhas no ensino/aprendizagem de línguas, focalizar as práticas sociais das interações cotidianas pode ser de extrema utilidade, ou, ao contrário, e paradoxalmente, apresentar-se como um enorme obstáculo. Por isso mesmo, essa é uma questão que merece atenção redobrada.

Dado o fato de que o sujeito encontra, em práticas sociais que lhe são familiares, um alto grau de previsibilidade e age, assim, segundo padrões que seriam mais estáveis em seu sistema cognitivo, lidar com a dinâmica de tais interações pode ser de interesse para desencadear processos de aprendizagem com reestruturação de esquemas cognitivos. Pesquisadores e professores podem depreender pistas desse processo de aprendizagem pela atitude responsiva dos sujeitos em formação. É porque consideram esse aspecto que muitos salientam a relevância de se lidar com os chamados "conhecimentos prévios" com os quais nossos alunos chegam às diferentes etapas da escolarização.

Por outro lado, considerando-se justamente seu alto de grau de previsibilidade e a familiaridade com a qual os sujeitos lidam com os artefatos simbólicos envolvidos nas práticas interacionais cotidianas, focalizá-las nos processos de ensino/aprendizagem pode vir a dificultar a desnaturalização de formas específicas de esquematismo e, portanto, impedir a emergência de conflitos cognitivos essenciais ao processo de aprendizagem. Em um trabalho que relata resultados de pesquisas com aprendizes, Doise e Mugny (1997) salientam que as situações de conflito sociocognitivo podem desencadear processos importantes de aprendizagem, porque levam os sujeitos a elaborarem instrumentos cognitivos com os quais os conflitos podem ser resolvidos.

Vejamos alguns comentários obtidos em atividades desenvolvidas por professores em formação, nas quais eles analisam situações de leitura e escrita de alunos da Educação Básica. No exemplo a seguir, registrado em atividade de diagnose, solicitava-se que os alunos, retomando 
reflexões desenvolvidas em períodos anteriores, delimitassem o que compreendiam por língua e linguagem ${ }^{11}$.

\section{Exemplo 1: conflito e construção de novos esquemas (Ana - $4^{\circ}$ período)}

(i) Língua refere a uma das tantas formas de manifestação concreta dos diversos sistemas de comunicação que a humanidade possui ou "construiu". Existem diversas línguas, pois cada comunidade possui a sua e a usa como instrumento para sua comunicação.

(ii) Linguagem é o modo de ação da língua, é com ela que se dá a interação, a troca de informações, conflito de pensamentos, enfim, usamos da linguagem para interagir tanto com os outros como com nós mesmos.

Pode-se assinalar certa inconsistência na delimitação conceitual de língua quando Ana afirma, por exemplo, que "cada comunidade possui a sua [lingua]". Qual a abrangência conceitual do vocábulo "comunidade”?, o que seria, nesse contexto, "possuir a sua lingua"?. Mas pode-se, também, assinalar que uma discussão orientada de suas respostas poderia reorganizá-las contribuindo para a solução do conflito que a leva tanto a assumir que há "uma língua única (de cada comunidade)" quanto a dizer que a linguagem é "o modo de ação da língua", a qual, por sua vez, é "(apenas) uma das formas de manifestação concreta que a humanidade [...] 'construiu"'.

Do mesmo modo, pode-se imaginar a importância de uma discussão orientada pelo professor (um processo de aprendizagem guiada, para retomar os termos de ROGOFF, 2005) para conduzir as

\footnotetext{
${ }^{11}$ Trata-se de um Curso de Letras de uma universidade de Minas Gerais em que os três primeiros semestres focalizam "a formação do usuário", ou seja, o desenvolvimento de habilidades de leitura e escrita, de fala e de escuta, e, por essa razão, privilegiam a oportunidade de os alunos participarem de diferentes situações de interação e de diferentes práticas de produção e recepção de textos - com foco especial nas que ganham vida no universo escolar e acadêmico. Nesses períodos, também, pretende-se que os alunos desenvolvam reflexões e sistematizem algumas das noções que lhes são essenciais no exercício profissional, dentre as quais a de língua, linguagem, variação e mudança lingüísticas, leitura, escrita, letramento, etc. Os nomes são, naturalmente, fictícios.
}

MATENCIO - Gêneros do discurso e apropriação de saberes... 
reflexões acerca das intervenções apresentadas a seguir, também enunciadas por professores em formação:

\section{Exemplo 2: heterogeneidade de respostas}

Ler é prazeroso, quem lê viaja, pois tem acesso a um mundo de informações para nos informar, divertir. (Carla)

A leitura, não importa como ela seja, escrita ou desenhada, é um meio de informar, comunicar e aprender. Quanto mais lemos mais aprendemos e maior é nossa facilidade de produzir textos, com eles falamos melhor uns com os outros. (Joana)

Acredito que a prática da leitura e da escrita seja um hábito que deve começar desde a infância. Eu não tive esse costume, contudo li alguns livros. Hoje tenho muito mais vontade e interesse de ler, porém não tenho tempo. (Wilson)

Os excertos provêm de uma aula em que os professores em formação, ainda no $2^{\circ}$ semestre do Curso, analisando a situação de leitura bem-sucedida por alunos da Educação Básica, focalizaram aspectos muito distintos da referida atividade de leitura, os quais, se não se encontram em contradição, merecem ser discutidos: (a) em relação às representações de leitura que retomam - como prazer e/ou informação; como aprendizagem que decorre da intensidade do acesso ou da construção de hábitos; e (b) em relação aos efeitos da leitura em situações efetivas de socialização, em que os sujeitos constroem uma relação com as práticas que recorrem à palavra escrita e com os gêneros de atividades em que emergem.

O que esses exemplos pretendem ressaltar é que as interações sociais são construtivas em relação aos processos de aprendizagem, na medida em que levem o sujeito-aprendiz a confrontar soluções diversas suas próprias ou de outros sujeitos - para um único problema, de ordem cognitiva ou social, e, a partir daí, seja levado a realizar ações que permitam escolhas dentre um conjunto de possibilidades.

A esse respeito, Doise e Mugny (1997) assinalam que os conflitos sociocognitivos que promovem efeitos produtivos em relação ao desenvolvimento cognitivo são aqueles em que a ação do sujeito se estrutura e se desenrola em atividades socializadas. Nessas situações, definidas pela heterogeneidade de respostas, o conflito sociocognitivo 
pode levar ao desenvolvimento em razão: (a) da potencialidade que têm para motivar ações e operações cognitivas que incidam não apenas sobre um "objeto", mas também, e principalmente, sobre posições e pontos de vista diferentes em relação a esse objeto; (b) da tomada de consciência, pelo sujeito, de respostas diferentes da sua, uma vez que a explicitação da diferença de posições assumidas nas situações sociais é, potencialmente, fonte de desequilíbrio, tanto social quanto cognitivo, e a tentativa de "resolver" o conflito pode desencadear o processo de reequilibração; e (c) da condição básica de tais situações para a construção de novos "instrumentos cognitivos".

Dessa perspectiva, assim como todo conhecimento social pressupõe funcionamento cognitivo, pode levar, porque se constitui com artefatos simbólicos dinamicamente construídos nas interações, a progressos na (co)ordenação cognitiva de objetos/instrumentos que medeiam essas práticas sociais. Ora, não se pode negar que a inserção social do aluno em situações de aprendizagem guiada, no âmbito de uma educação lingüística crítica, pode promover não apenas a construção de esquemas de ação que o auxiliem nas novas situações com as quais vier a se deparar, como também, e sobretudo, possibilitar uma atitude reflexiva em relação ao que os atores sociais fazem quando usam a língua(gem) e ao por que fazem o que fazem.

\section{DAS QUESTÕES TEÓRICAS ÀS PRÁTICAS}

Eventuais críticas ao que aqui foi proposto poderiam remeter à série de contingências que cercam a produção acadêmico-científica, anteriormente referida. Alguns leitores poderiam questionar, por exemplo, se nós, formadores e professores da Educação Básica, estaríamos em condições de: (a) orientar reflexões consistentes em relação à seriação e ao seqüenciamento de conteúdos ao longo da escolarização; (b) mapear e propor estratégias de abordagem de conteúdos que levem a efeito propostas de ensino/aprendizagem baseadas nos princípios defendidos; e (c) elaborar projetos de ensino/aprendizagem que permitam a implantação de diretrizes e matrizes curriculares que daí resultem. 
Do que foi dito ao longo deste texto, interessa-me reter, particularmente, os argumentos relativos à imbricação entre os processos cognitivos subjacentes aos usos da linguagem e os processos de socialização, que procuram sustentar que os esquemas de ação e os modelos mentais estão intrinsecamente ligados às práticas sociodiscursivas, que, por sua vez, implicam a apropriação de artefatos simbólicos pelos (e com os) quais os sujeitos compreendem e organizam seu universo espácio-temporal e interagem nos (com os) diferentes espaços e tempos sociais.

É esse raciocínio que permite sustentar que, nos processos formais de ensino/aprendizagem, deve ser abandonada, de uma vez por todas, a idéia de que as tarefas e atividades propostas precisam visar ao "treinamento" dos alunos para a construção de habilidades de leitura e escrita, de fala e escuta, ou de análise de textos. As habilidades - e competências subjacentes - não se ensinam, se aprendem; ou seja, constroem-se pelo sujeito como esquemas de ação e modelos estáveis de representação mental, à luz de padrões interacionais também estabilizados. Segundo essa concepção, as práticas em sala de aula devem ter como eixo, como se procurou discutir, tarefas e atividades de ensino/aprendizagem que orientem o sujeito-aprendiz a compreender as dinâmicas das interações sociais, à luz dos possíveis objetivos em jogo e das potenciais estratégias, habilidades e competências colocadas em cena. Esse procedimento, que inclui a emergência de conflitos sociocognitivos e as tentativas de solucioná-los, pode motivar o aprendiz a (re)dimensionar suas próprias expectativas e seus projetos de ação, de médio e longo prazo, bem como motivá-lo a (desejar?) inserir-se nas práticas sociodiscursivas assumindo posições identitárias responsivoativas (como diria BAKHTIN) ${ }^{12}$. Esse, parece-me, seria o caminho possível para efetivar o que se tem almejado já há algum tempo: uma educação lingüística (obviamente, crítica!).

Ainda que essa perspectiva saliente a importância da flexibilidade nos projetos de ensino/aprendizagem, até porque defende a autonomia dos projetos individuais dos alunos, há eixos claramente delineados

\footnotetext{
${ }^{12}$ Isso significa, portanto, que devem ser abandonadas as "leituras" das propostas de parametrização curricular que focalizem a construção de seqüências didáticas em séries de tarefas e atividades que pretendam "treinar" os alunos.
} 
quando se defende sua adoção, os quais estão vinculados ao que se sabe sobre como: (a) os sujeitos aprendem uma língua e desenvolvem a capacidade de linguagem em sua socialização; (b) as representações sociais e individuais se imbricam; e (c) o discurso - e os saberes (em) que (se) produz - é o "tesouro" pelo qual se luta nas muitas arenas que configuram a sociedade.

Ora, um país precisa, obviamente, ter um projeto consistente e claro de como pretende formar seus cidadãos. Portanto, uma base nacional comum para o ensino de línguas, mais do que uma necessidade, é uma posição política ética. Defender uma base matricial do currículo comum em nível nacional, por sua vez, pressupõe uma organização integradora das diferentes disciplinas científicas e escolares - em eixos inter, trans e multidisciplinares -, pela qual se contemple a plasticidade dos saberes e a mobilidade que caracteriza (ou que, espera-se, deveria caracterizar) as instâncias e instituições que os produzem. A integração de diferentes campos disciplinares, obviamente, pressupõe trabalho coletivo, por actantes que representem, efetivamente, as instâncias de produção discursiva em fóruns de diálogo a serem incorporados e legitimados pelas secretarias municipais e estaduais e, sobretudo, pelo Ministério da Educação.

Uma organização curricular que envolva uma base nacional a ser interpretada, ampliada e circunstanciada por projetos locais de currículos pressupõe uma dinâmica em que não cabem salários defasados, regulamentação profissional que deixe brechas para a descontinuidade no cotidiano escolar (como ocorre atualmente, por exemplo, visto que, por precisarem completar sua carga em várias escolas, os professores pouco podem de fato engajar-se nos projetos em andamento nessas instituições). Uma proposta como essa prevê a construção de um projeto coletivo de intervenção para a formação dos alunos; prevê, portanto, escolas que, além de ter um corpo docente efetivo, tenham um efetivo "corpo" docente.

Do ponto de vista dos conteúdos, uma proposta como essa representa a organização seqüencial e seriada de conteúdos que, por sua vez, possam representar, para os alunos, objetos de aprendizagem significativos, que possibilitem não apenas que eles "descubram" a importância do conhecer como, mas também conhecer o que conhecem e como seus saberes podem fundamentar seus projetos de vida - criando 
condições para sua inclusão e seu empoderamento, para sua atuação na transformação social.

Alguns dos eixos que, certamente, devem sustentar a construção desses projetos político-pedagógicos foram esboçados na discussão teórica acerca da relação entre gêneros do discurso e processos de socialização. Além de se prever a incorporação de diferentes manifestações da linguagem e não só as ligadas à fala e à escrita - o que pressupõe tarefas e atividades em que se destaquem as inter-relações entre a fala, a escrita e outros sistemas semióticos -, a valorização da diversidade de idéias, cultura e formas de expressão deve criar condições para que se explore a interdependência de formas, usos e funções de linguagem. Mas é certo, também, que, (n)as demandas regionais e locais, são determinantes as escolhas relativas a seriação, seqüenciação, anterioridade, hierarquia e organização de conteúdos. Nesse aspecto específico, o que aqui se propôs conduziria a formas de organização de conteúdos que envolveriam agrupamentos de textos segundo recortes muito variados em relação a, por exemplo: temas abordados; seqüências textuais que os configuram; práticas de linguagem em que emergem; gêneros do discurso que atualizam; comunidades que os produzem; espaço e/ou tempo de produção; mídias e suportes nos quais circulam; domínios ou esferas de atividades em que emergem. Tanto os agrupamentos textuais quantos os recortes dos objetos de ensino e de aprendizagem são, dado o que se discutiu, dependentes de seu grau de complexidade e do estágio em que se encontram os alunos.

$\mathrm{O}$ que focalizar em relação aos textos que constituem tais agrupamentos depende, é claro, tanto de objetivos específicos da tarefa e da atividade (da unidade de ensino e de sua localização no bimestre ou ano escolar) quanto de objetivos mais gerais de formação (etapa em que se encontram os alunos). De qualquer maneira, os trabalhos em nosso campo de estudos fornecem um quadro de referências bastante amplo e consistente em relação aos operadores lingüísticos, textuais e discursivos com os quais lidamos na produção de sentidos, os quais são, sem dúvida alguma, cruciais nas dinâmicas das interações e, conseqüentemente, para o desenvolvimento da linguagem pelo sujeito (e do sujeito pela linguagem!). Transformar tais operadores em objetos de ensino/aprendizagem parece, por isso mesmo, essencial. Dentre as categorias fundamentais para a compreensão das relações estáveis entre 
formas e sentidos, texto e contexto, podem-se destacar (independentemente de estarem em jogo textos escritos ou falados) o recurso estratégico: (a) aos mecanismos de formulação textual e de reformulação do texto (envolvendo operações de substituição, deslocamento, apagamento e acréscimo) e aos processos que lhes são adjacentes; (b) a formas de textualização da referência pessoal, dos mecanismos enunciativos, das dimensões espácio-temporais e da modalização; e (c) aos efeitos da seleção lexical, do registro lingüístico, dos operadores de segmentação e articulação textual. No que respeita às práticas escritas, não podemos ignorar a relevância de se estudarem os recursos que sustentam as diversas topografias textuais; ou seja, recursos de um sistema construído, historicamente, com (e para) a tecnologia da escrita, visando a otimizar determinadas de suas práticas, envolvendo ortografia e pontuação, assim como a segmentação e a disposição do texto em orações, períodos, parágrafos, colunas, seções e capítulos; ou, ainda, a integração de elementos verbais aos provenientes de outros sistemas semióticos.

Como certamente muitos leitores irão concluir, o que aqui se discutiu não traz propriamente novidades; mais do que isso, pode-se mesmo afirmar que a tentativa de articular a discussão teórica às práticas em sala de aula remete a enunciados bastante conhecidos, que circulam com outros modos de formulação: "é necessário que o país tenha um projeto consistente de educação"; "O professor precisa ser bem formado"; "os salários precisam ser justos"; "está na hora de elaborarmos um plano de carreira real para os professores"; "é preciso oferecer uma formação crítica"; "o ensino deve ser contextualizado, para fazer sentido para o aluno"; "o aluno precisa descobrir o prazer da leitura e do conhecimento". Não pretendo dizer o contrário; aliás, ao que tudo indica, retomadas e deslocamentos são mecanismos centrais tanto na produção de conhecimento quanto nas tentativas de se defenderem mudanças em relação às representações sociais.

\section{CONSIDERAÇÕES FINAIS}

Gostaria de finalizar este texto remetendo ainda uma vez a Foucault (1998), mais especificamente, quando trata das formas de 
controle, organização e (re)distribuição dos discursos, por aquelas que são, para ele, as "sociedades" que comentam e difundem os saberes. Gostaria, particularmente, de relacionar este dizer, em que certamente nos reconhecemos - seja porque comentamos e difundimos saberes, seja porque ora assumimos as formas de controle do discurso, ora não podemos escapar delas -, à perspectiva do autor quando aborda as transformações por que passa o sujeito da "estrutura", que se altera, nos processos históricos, justamente porque é estruturado em linguagem. Gostaria, assim, de ler Foucault a meu modo, e dizer, com ele, que o sujeito que nesse momento histórico se estrutura em linguagem não é o da busca do verdadeiro e do falso, porque o discurso de que há "verdade" não é mais o do poder. O poder, hoje como antes, não se alcança pela "verdade" ou "falsidade" do dito, mas porque se tem o direito ao (próprio?) discurso. Compreendemos assim por que, enquanto muitos desacreditam da verdade possível da ética, outros ainda acreditam na verdade ou falsidade das coisas. Se retomo, para comentar, enunciados e formulações, crenças e argumentos, é porque este me parece ser um percurso necessário para compreender - e alterar - esse nosso fazer cotidiano no ensino de uma língua.

\section{REFERÊNCIAS}

BAKHTIN, M. Estética da criação verbal. São Paulo: Martins Fontes, 2000 [1. edição de 1979].

BRONCKART, J.-P. Atividade de linguagem, textos e discursos: por um interacionismo sócio-discursivo. São Paulo: EDUC, 1999.

. Une introduction aux théories de l'action. Genebra: UNIGE, 2005.

. Atividade de linguagem, discurso e desenvolvimento humano.

Campinas, SP: Mercado de Letras, 2006.

. O agir nos discursos: das concepções teóricas às concepções dos trabalhadores. Campinas, SP: Mercado de Letras, 2008.

CELANI, M. A. A. Afinal, o que é Lingüística Aplicada? In: PASCHOAL, M. S.; CELANI, M. A. A. (Orgs.). Lingüística Aplicada: da aplicação à Lingüística interdisciplinar. São Paulo: EDUC, 1992. p. 15-23. 
CHISS, J.-L.; PUECH, C. Le langage et ses disciplines: $\mathrm{XIX}^{\mathrm{e}}-\mathrm{XX}^{\mathrm{e}}$ siècle. Paris ; Bruxelles: De Boeck \& Larcier, 1999.

CORDIER, F. Représentation cognitive \& langage: une conquête progressive. Paris: Armand Colin, 1994.

DOISE, W. ; MUGNY, G. Psychologie sociale et développement cognitif. Paris: Armand Colin, 1997.

FOUCAULT, M. A ordem do discurso. São Paulo: Loyola, 1998.

HOUDÉ, O. Les 100 mots de la psychologie. Paris: PUF, 2008.

KLEIMAN, A. B. O ensino de línguas no Brasil. In: PASCHOAL, M. S.;

CELANI, M. A. A. (Orgs.). Lingüística Aplicada: da aplicação à Lingüística interdisciplinar. São Paulo: EDUC, 1992. p. 25-36.

- (Org.). A formação do professor: perspectivas da lingüística aplicada.

Campinas, SP: Mercado de Letras, 2001.

; MATENCIO, M. L. M. (Orgs.). Letramento e formação do

professor: práticas discursivas, representações e construção do saber. Campinas, SP: Mercado de Letras, 2005.

KOCH, I. V. Desvendando os segredos do texto. São Paulo: Cortez, 2002.

LEONTIÉV, A. O desenvolvimento do psiquismo. Lisboa: Horizonte Universitário, 1978.

MACHADO, A. R. (Org.). O ensino como trabalho: uma abordagem discursiva. Londrina, PR: Eduel, 2004.

MATENCIO, M. L. M. Estudo da língua falada e aula de língua materna: uma abordagem processual da interação professor/alunos. Campinas, SP:

Mercado de Letras, 2001.

. Referenciação e retextualização: um estudo do resumo e da resenha. In: CONGRESSO INTERNACIONAL DA ABRALIN, 3. Rio de Janeiro, RJ.

Anais... Rio de Janeiro: UFRJ, 2003. Disponível em:

<http://www.letras.ufrj.br/ abralin/fale.htm>.

Práticas discursivas, gêneros do discurso e textualização. Revista

Estudos Lingüísticos, XXXV: “52. Seminário do Grupo de Estudos do Estado de São Paulo, 2005. Disponível em: <www.gel.org.br>.

Os estudos dos gêneros do discurso: leituras e efeitos da abordagem bakhtiniana. In: EMEDIATO, W.; MACHADO, I. L.; MENEZES, W. (Orgs.). 
Análise do Discurso: gêneros, comunicação e sociedade. Belo Horizonte: UFMG, 2006a. p. 215-226.

. Formação do professor e representações sociais de língua(gem): por uma lingüística implicada. In: CORREA, M. L.; BOCH, F. (Orgs.). Revista de Filologia e Lingüística Portuguesa, v. 1, p. 439-449, 2006b.

MONDADA, L.; DUBOIS, D. Construção de objetos de discurso e categorização: uma abordagem dos processos de referenciação. In:

CAVALCANTE, M. M.; RODRIGUES, B. B.; CIULLA, A. (Orgs.).

Referenciação. São Paulo: Contexto, 2003. p. 17-52.

MORTIMER, E.; SMOLKA, A. L. (Orgs.). Linguagem, cultura e cognição. Belo Horizonte: Autêntica, 2001.

RAJAGOPALAN, K. Por uma lingüística crítica: linguagem, identidade e a questão ética. São Paulo: Parábola, 2003.

ROGOFF, B. A natureza cultural do desenvolvimento humano. Porto Alegre: ARTMED, 2005.

SCHNEUWLY, B. Le langage écrit chez l'enfant. Genebra: Delachaux \& Niestle, 1988.

Gêneros e tipos de discurso: considerações psicológicas e ontogenéticas. In: SCHNEUWLY, B.; DOLZ, J.; e colaboradores. Gêneros orais e escritos na escola. Campinas, SP: Mercado de Letras, 2004. p. 21-40.

VYGOTSKY, L. Pensamento e linguagem. São Paulo: Martins Fontes, 1989. A formação social da mente. São Paulo: Martins Fontes, 1991.

Recebido em 16/08/08. Aprovado em 23/09/08.

Title: Genres and the appropriation of knowledge: recognizing language practices in the classroom

Author: Maria de Lourdes Meirelles Matêncio

Abstract: Any social activity presupposes linguistic actions. It seems to be essential, therefore, that L1 teaching classes at different levels should focus on the different teaching levels and on interactional social dynamics as a means of getting the intended learning processes underway. From this point of view, this article discusses the relevance of using genres - conceived as forms of interactional activity - in order to assure the construction of essential knowledge for individual action in the diverse language practices a social subject may face.

Keywords: genre; literacy; language practice; activity. 
Titre: Genres du discours et appropriation de savoirs: (re)connaître les pratiques du langage en salle de classe

Auteur: Maria de Lourdes Meirelles Matêncio

Résumé: Toutes les activités sociales présupposent la réalisation d'actions de langage. Ainsi, il paraît être essentiel, que les cours de langue maternelle soient centrés dans les niveaux différents d'enseignement visés. Dans la perspective de ce point de vue, ce texte discute l'avantage avec lequel on travaille les genres du discours - conçus comme genres d'activités interactionnelles -, à fin d'assurer la construction de savoirs essentiels pour le rôle du sujet dans différentes pratiques de langage avec lesquelles il se trouve devant.

Mots-clés: genre du discours; littératie; pratique de langage; activité.

Título: Géneros del discurso y apropiación de saberes: (re)conocer las prácticas lenguajeras en sala de aula

Autor: Maria de Lourdes Meirelles Matêncio

Resumen: Toda actividad social presupone la realización de acciones de lenguaje. Parece ser esencial, por esa razón, que las clases de lengua materna se centran, en los diferentes niveles de enseño, en las dinámicas sociales de interacción como formas de desencadenar los procesos de aprendizaje visados. A la luz de ese punto de vista, este texto discute la relevancia de trabajar con los géneros del discurso - concebidos como géneros de actividades interracionales -, a fin de garantir la construcción de saberes esenciales para la actuación del sujeto en las diversas prácticas de lenguaje con las cuales venga a depararse.

Palabras-clave: género del discurso; literacia; práctica de lenguaje; actividade.

MATENCIO - Gêneros do discurso e apropriação de saberes... 